\title{
STUDY ON CORRELATION OF CD4 COUNT WITH MALIGNANCY IN HIV
}

\author{
Kiran $\mathrm{VH}^{1}$, John T. Ramapuram², Krishna Prasad ${ }^{3}$
}

\section{HOW TO CITE THIS ARTICLE:}

Kiran VH, John T. Ramapuram, Krishna Prasad. "Study on Correlation of CD4 Count with Malignancy in HIV". Journal of Evolution of Medical and Dental Sciences 2015; Vol. 4, Issue 63, August 06; Page: 10883-10886, DOI: $10.14260 /$ jemds/2015/1573

\begin{abstract}
BACKGROUND: Malignancies are increasing in HIV patients and Opportunistic infections are decreasing with the use of ART (Anti-Retroviral Therapy). CD4 count is a simple immunological marker useful in HIV patients to assess the disease severity. The study was aimed to know whether CD4 count has any correlation with the incidence of malignancy in HIV patients. METHODOLOGY: Retrospective study was carried out; Using semi-structured proforma, data was collected from Medical Records Department. 40 HIV subjects diagnosed with malignancy was obtained. Fisher's exact test was used to analyze the data statistically. RESULTS: In our study out of 40 subjects with malignancy $80 \%$ had CD4 count $<200$. Among the patients with AIDS defining malignancy $89 \%$ (16 patients) had CD4 count $<200$. Among patients with Non AIDS defining malignancy, around 73\% (16 patients) had CD4 count $<200$. The association of type of malignancy with CD4 count is statistically not significant $(\mathrm{p}=0.358)$ but it has positive correlation. Out of 40 patients 21 were in HIV stage 4 . Among the patients with stage 4 HIV, around $86 \%$ (18) had CD4 count<200. CONCLUSION: CD4 count has Positive correlation with the Incidence of Malignancy in HIV patients.
\end{abstract}

KEYWORDS: ART, CD4 Count.

INTRODUCTION: Cancers such as Kaposi's sarcoma were among the initial clinical diagnosis that led to the recognition of Human Immunodeficiency Virus (HIV) infections in 1981.[1] HIV is the etiological agent of AIDS; it belongs to the family of human Retroviruses (Retroviridae) and the subfamily of Lentiviruses. AIDS defining cancers such as Kaposi's sarcoma, Non-Hodgkin's lymphoma and Invasive cervical cancer are the predominant cancers affecting the HIV positive people.[2,3] The incidence of malignancies among Human Immunodeficiency virus (HIV) infected patients is known to be higher than in the general population.[4,5,6] Around 30\% to 40\% of HIV patients during their life time develop malignancy. ${ }^{[7]}$ During the past decade the improved survival consequent to the use of Antiretroviral therapies (ART) has led to the emergence of a variety of age related diseases, including cardiovascular diseases and cancers.[8,9,10] In the 1980's studies suggested that malignancies would cause a second epidemic, which was realized with the occurrence of Kaposi's sarcoma and lymphoma.[11] India accounts for the second largest number of HIV/AIDS patients in the world, but studies performed in the area of HIV related malignancies are few,[12] hence the need for study and mainly to identify simple immunological tests like CD4 count has any predictive significance in relation to incidence of malignancy in HIV.

MATERIALS AND METHODS: Retrospective study was carried out between January 2012 to July 2013. From the Institutional Ethics Committee of KMC (Kasturba medical college), Mangalore a written approval was taken for collecting the data. Written consent was also taken from the Head of Medical Records Department KMC hospital Attavar and Government Wenlock Hospital Mangalore. 1500 case files of HIV positive (VCTC positive) patients registered in MRD of kmc hospital Mangalore 


\section{ORIGINAL ARTICLE}

and Govt Wenlock Hospital from January 2001 up to December 2011 were studied. Among them 40 cases of Malignancy (Biopsy proven) in HIV were detected. Data was collected using a semi structured Proforma which includes basic information of the subjects like Name, Age, Sex and residence and specific information like CD4 count ART status, Type of malignancy.

STATISTICAL METHOD: Data was analyzed using "Fishers exact "test.

RESULTS: Malignancy in HIV patients obtained from all combined case files of HIV subjects (1500) studied was 40. In our study Mean age of the study subjects is 44yrs. Among 40 subjects with malignancy in HIV 62\% were males and 38\% were females. 95\% were enrolled on ART and only 5\% were not on ART. In our study out of 40 patients with malignancy $80 \%$ had CD4 count $<200,12 \%$ had CD4 count between 200-349 and only 8\% had CD4 count 350 and above as shown in table 1 . In our study, among the patients with AIDS defining malignancy 89\% (16patients) had CD4 count $<200$. Among patients with Non AIDS defining malignancy, around 73\% (16patients) had CD4 count $<200$. The association of type of malignancy with CD4 count is statistically not significant $(p=0.358)$ but it has positive correlation as shown in table 2 . Out of 40 patients 21 were in HIV stage 4 . Among the patients with stage 4 HIV, around $86 \%$ (18) had CD4 count $<200$ as shown in table 3. CD4 count with stage of HIV has Positive correlation indicating incidence of malignancy in advanced stages of HIV, but it is not so statistically significant $(\mathrm{p}=0.487)$.

\section{CHART SHOWING CD4 COUNT:}

\begin{tabular}{|c|c|c|}
\hline CD4 COUNT & Frequency & Percent \\
\hline$<200$ & 32 & 80.0 \\
\hline $200-349$ & 5 & 12.5 \\
\hline 350 and above & 3 & 7.5 \\
\hline Total & $\mathbf{4 0}$ & $\mathbf{1 0 0 . 0}$ \\
\hline \multicolumn{3}{|c}{ Table 1} \\
\end{tabular}

\section{COMPARISON OF CD COUNT WITH TYPE OF MALIGNANCY:}

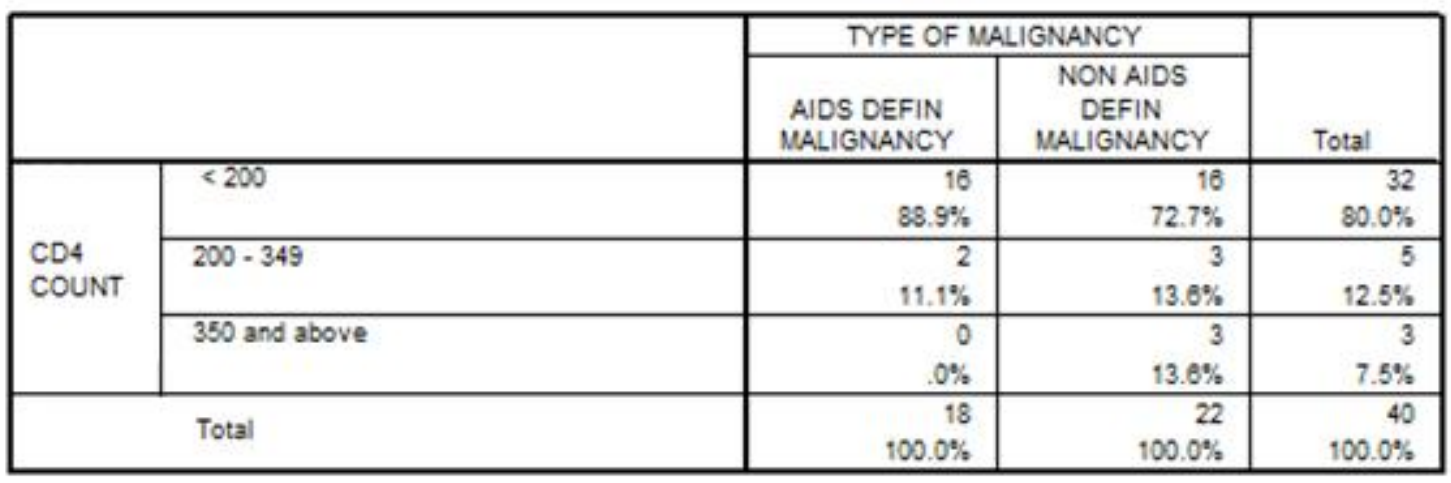

\section{Table 2}

Fishers exact test $\mathrm{p}=0.358$, NS (not significant) 


\section{COMPARISON OF CD4 COUNTS WITH STAGE OF HIV:}

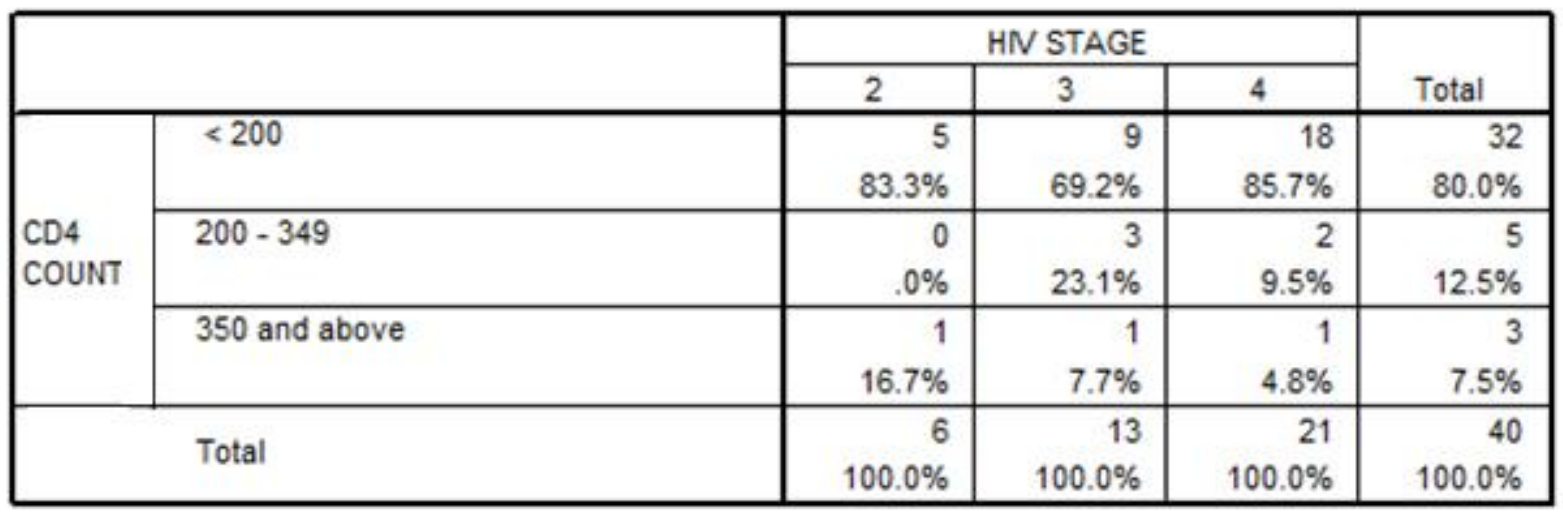

Table 3

Fishers exact test $\mathrm{p}=0.487$, NS.

DISCUSSION: In our study Majority (53\%) of patients were falling into WHO stage 4, and among stage 4 patients, $86 \%$ (18) had CD4 count <200. this clearly indicates that incidence of malignancy in HIV patients is more predominant in profound immunodeficiency as indicated by low CD4 count, this is in concordance with the study done by Venkatesh KK et al,[13] who stated in his study that cancers developed in HIV patients when they were having low nadir CD4 count. 80\% of malignancy patients in our study had a CD4 count less than 200 indicating that immunodeficiency as marked by CD4 count is a predictor for development of malignancy this matches with the study done by M. C. F. Prosperi et al.[14] In our study it was observed that patients with AIDS defining malignancies had much more pronounced low CD4 count than patients with Non AIDS defining malignancies, this matches with the study done by M. C. F. Prosperi et al.[14]

CONCLUSION: CD4 count has positive correlation with the incidence of malignancy in HIV patients, so CD4 count can be considered as a simple predictor of malignancy in HIV patients in a developing country like India.

\section{REFERENCES:}

1. Centers for disease control (CDC). Kaposi's sarcoma and Pneumocystis pneumonia among homosexual men - New York City and California. MMWR Morb wkly Rep 1981; 30:305-08.

2. Frisch M, Biggar RJ, Engels EA, Goedart JJ. Association of Cancer with AIDS related Immunosuppression in adults. JAMA. 2001Apr4; 285(13): 1736-45.

3. International Collaboration on HIV and Cancer. Highly active anti-retroviral therapy and incidence of cancer in Human Immuno Deficiency Virus - Infected Adults. J Natl Cancer Inst. 2000 Nov 15; 92(22):1823-30.

4. Patel P, Hanson DL, Sullivan PS, et al; Adult and Adolescent Spectrum of Disease Project and HIV Outpatient study investigators. Incidence of types of cancer among HIV - infected persons compared with the general population in the United States, 1992-2003. Ann intern med.2008 May 20; 148(10):728-36. 


\section{ORIGINAL ARTICLE}

5. Serraino D, Piselli P, Busnach G, et al; Immunosuppression and Cancer study group. Risk of cancer following immunosuppression in organ transplant recipients and in HIV -positive individuals in southern Europe. Eur J cancer 2007; 43(14):2117-23.

6. Engels EA, Pfeiffer RM, Goedert JJ, et al; for the HIV/AIDS cancer match study. Trends in cancer risk among people with AIDS in the United States 1980-2002. AIDS 2006 Aug 1; 20(12):164554.

7. Spano JP, Atlan D, Breau JL, Farge D. AIDS and Non AIDS related malignancies: A new vexing challenge in HIV- positive patients. Part I: Kaposi 'sarcoma, Non Hodgkins's lymphoma and Hodgkin's Lymphoma. Eur J Int Med. 2002May; 13(3): 170-79.

8. Herida M, Mary-Krause M, Kaphan R, et al. Incidence of Non-AIDS Defining cancers before and during The Highly Active Antiretroviral Therapy Era in A Cohort of Human Immunodeficiency Virus - Infected patients. J Clin Oncol 2003 Sep 15; 21(18):3447-53.

9. Mayor AM, Gomez MA, Rios-Olivares E, Hunter-Mellado RF. AIDS Defining Neoplasm prevalence in a cohort of HIV-infected patients, before and after Highly Active Antiretroviral Therapy. Ethn Dis 2008:18:S2189-94.

10. Ives NJ, Gazzard BG, Easterbrook PJ. The changing pattern of AIDS defining illnesses with the introduction of Highly Active Antiretroviral Therapy (HAART) in a London Clinic. J Infect 2001; 42(2):134-39.

11. Monfardini S, Vaccher E, Pizzocaro G, et al. Unusual Malignant tumors in 49 patients with HIV infection. AIDS 1989; 3: 449-52.

12. Dhir AA, Sawant SP. Malignancies in HIV: The Indian Scenario. Curr Opin Oncol.2008 Sep; 20(5):517-21.

13. Venkatesh KK, Saghayam S, Devaleenal B et al, Spectrum of Malignancies among HIV infected patients in South India, Indian J Cancer 2012 JAN-MAR;49(1):176-80.

14. M.C.F. Prosperi A, Cozzi-Lepri A, Castagna et al, Incidence of Malignancies in HIV infected patients AND Prognostic role of current CD4 cell count evidence from A Large Italian Cohort Study, CID 2010;50(9):1316-21.

\section{AUTHORS:}

1. Kiran VH

2. John T. Ramapuram

3. Krishna Prasad

\section{PARTICULARS OF CONTRIBUTORS:}

1. Junior Resident, Department of Internal Medicine, KMC, Mangalore.

2. Professor \& Unit Head, Department of Internal Medicine, KMC, Mangalore.

3. Associate Professor, Department of Medical Oncology, KMC, Mangalore.

\author{
NAME ADDRESS EMAIL ID OF THE \\ CORRESPONDING AUTHOR: \\ Dr. Kiran VH \\ S/o. Venkataramana S, \\ Sneha Nilaya, $1^{\text {st }}$ Cross, \\ Sharavathi Nagar, \\ Shimoga. \\ E-mail: vajrabahu2886@gmail.com
}

Date of Submission: 30/07/2015.

Date of Peer Review: 31/07/2015.

Date of Acceptance: 01/08/2015.

Date of Publishing: 04/08/2015.

FINANCIAL OR OTHER COMPETING INTERESTS: None 